\title{
Strength and Durability Characteristics of Cement Composites with Recycled Water and Blast Furnace Slag Aggregate
}

\author{
Se-Jin Choi * (D), Sung-Ho Bae, Jae-In Lee and Ji-Hwan Kim \\ Department of Architectural Engineering, Wonkwang University, 460 Iksan-daero, Iksan 54538, Korea; \\ caos1344@naver.com (S.-H.B.); wodls103@naver.com (J.-I.L.); 3869kjh@naver.com (J.-H.K.) \\ * Correspondence: csj2378@wku.ac.kr; Tel.: +82-63-850-6789
}

Citation: Choi, S.-J.; Bae, S.-H.; Lee,

J.-I.; Kim, J.-H. Strength and

Durability Characteristics of Cement Composites with Recycled Water and Blast Furnace Slag Aggregate.

Materials 2021, 14, 2156. https://

doi.org/10.3390/ma14092156

Academic Editor: F. Pacheco Torgal

Received: 19 March 2021

Accepted: 21 April 2021

Published: 23 April 2021

Publisher's Note: MDPI stays neutral with regard to jurisdictional claims in published maps and institutional affiliations.

Copyright: (c) 2021 by the authors. Licensee MDPI, Basel, Switzerland. This article is an open access article distributed under the terms and conditions of the Creative Commons Attribution (CC BY) license (https:// creativecommons.org/licenses/by/ $4.0 /)$.

\begin{abstract}
Recently, interest in sustainable development has been increased. In this regard, efforts have been made to prevent environmental pollution, and research on the recycling of construction industry byproducts has been actively conducted in the construction industry. In South Korea, about 20 million tons of waste wash water from the ready-mixed concrete production process are generated, and some of them are recycled using recycling facilities in a ready-mixed concrete plant, but a significant portion of them is discharged or landfilled without permission, causing environmental problems. To increase the recycling rate of steel slag and reduce environmental pollution in the construction industry, we simultaneously applied blast furnace slag fine aggregate (BSFA) and recycled water (RW) to cement mortar. In this study, to examine the feasibility of RW and BSFA, we evaluated the fluidity, compressive strength, tensile strength, drying shrinkage, carbonation depth, and chloride penetration resistance of cement mortar using RW and BSFA. From the test results, the 28-day compressive strengths of all samples using RW and BSFA were higher than that of the control sample. In the case of samples using RW, as the BSFA replacement ratio was increased, the carbonation depth of the samples decreased. Therefore, when RW and BSFA are used properly, the mechanical properties of cement mortar, carbonation resistance, and chloride ion penetration resistance are expected to be effectively improved.
\end{abstract}

Keywords: recycled water; blast furnace slag aggregate; strength; cement composite; drying shrinkage; carbonation

\section{Introduction}

Recently, interest in sustainable development has increased. In addition, owing to the immense growth of the global concrete industry, the shortage of natural aggregates has emerged as a serious problem.

In this regard, efforts have been made to prevent environmental pollution, and research on the recycling of construction industry byproducts has been actively conducted in the construction industry [1-4]. Among the byproducts of the construction industry, about 20 million tons of waste wash water from the ready-mixed concrete production process are generated in Korea, and some of them are recycled using recycling facilities in a ready-mixed concrete plant, but a significant portion of them is discharged or landfilled without permission, causing environmental problems. Waste wash water is divided into recycled water (RW), sludge water, supernatant water, and sludge contents [5], and various studies have reported using recycled wash water.

Franco et al. [6] investigated the recycling of waste wash water generated in a readymixed concrete plant, and as a result, using RW in concrete was found to reduce concrete capillary water absorption and improve durability.

Yang et al. [7] reviewed the durability and mechanical properties of concrete using RW and reported that mixing up to $8 \%$ of sludge contents did not affect freezing and thawing resistance. 
Ekolu et al. [8] investigated the feasibility of RW that satisfies the ASTM C 94 standards and reported that the compressive strength of mortar increased with the mixing ratio of RW.

Oh et al. [9] evaluated the characteristics of lightweight aggregate mortar using RW as prewetting water for artificial lightweight aggregates. Based on the result of the experiment, it was reported that the artificial lightweight aggregate mortar using RW with a sludge content of $5 \%$ showed higher compressive strength and carbonation resistance than the control sample.

Meanwhile, studies on alternative aggregate resources were conducted owing to the recent shortage of natural aggregates for concrete [10,11], and some studies on using blast furnace slag, a byproduct of the steel industry, as aggregates for concrete were reported [12-15].

Park et al. [11] reviewed the utility of coal gasification slag (CGS) as a fine aggregate for concrete and reported that, based on its chemical composition, CGS generally satisfies the criteria posed by the standards concerning the number of harmful substances, except for $\mathrm{SO}_{3}$.

Valcuende et al. [13] evaluated the shrinkage characteristics of self-compacting concrete using blast furnace slag aggregate and reported that autogenous and drying shrinkage increased with the amount of slag.

However, studies on mortar or concrete using steel slag aggregate and RW were not reported. To increase the recycling rate of steel slag and reduce environmental pollution in the construction industry, we intend to apply blast furnace slag fine aggregate (BSFA) and RW to cement mortar simultaneously. In the literature, it is reported that the high alkalinity of RW can improve the reactivity of blast furnace slag powder [16]. However, if blast furnace slag is used for cement composites in the aggregate form rather than in the powder form, the characteristics of cement mortar are expected to be different.

This study examines the feasibility of RW and BSFA in cement mortar, the fluidity, compressive strength, tensile strength, drying shrinkage, carbonation depth, and chloride penetration resistance of cement mortar using RW and BSFA were evaluated. This research, including RW and BSFA, brings novelty to the eco-friendly construction materials research field.

\section{Materials and Methods}

\subsection{Materials}

The cement used in this study was ordinary Portland cement (OPC), manufactured by Asia Co. (Seoul, Korea). As fine aggregates, natural sand with a specific gravity of 2.6 and a fineness modulus of 2.45 and a BSFA with a specific gravity of 2.8 and a fineness modulus of 2.3 generated in the form of fine aggregates from P Company (Seoul, Korea) was used. In the case of RW, by referring to the previous literature [9], sludge with a ratio of cement and sand fines (lower than $0.15 \mathrm{~mm}$ ) of $4: 1$ was prepared (Table 1), and the sludge content was fixed at $5 \%$ in RW. Thereafter, RW with a sludge content of 5\% was used as the mixing water. Tables 2 and 3 show the chemical composition and physical properties of the cement and fine aggregates used in this study. Figure 1 shows the shape and SEM image of BSFA. Figure 2 shows the particle size distribution of each aggregate.

Table 1. Sludge composition.

\begin{tabular}{ccccc}
\hline Mix & $\begin{array}{c}\text { W/C } \\
(\%)\end{array}$ & $\begin{array}{c}\text { Water } \\
(\mathbf{g})\end{array}$ & $\begin{array}{c}\text { Cement } \\
(\mathbf{g})\end{array}$ & $\begin{array}{c}\text { Sand Fines } \\
(\mathbf{g})\end{array}$ \\
\hline Sludge & 50 & 200 & 400 & 100 \\
\hline
\end{tabular}

Table 2. Chemical composition of cement.

\begin{tabular}{ccccccc}
\hline Type & $\mathrm{SiO}_{2}$ & $\mathrm{Al}_{2} \mathbf{O}_{3}$ & $\mathrm{Fe}_{2} \mathbf{O}_{3}$ & $\mathrm{CaO}$ & $\mathbf{M g O}$ & $\mathbf{K}_{\mathbf{2}} \mathbf{O}$ \\
\hline OPC & 17.43 & 6.50 & 3.57 & 64.40 & 2.55 & 1.17 \\
\hline
\end{tabular}


Table 3. Physical properties of fine aggregates.

\begin{tabular}{cccc}
\hline Type & $\begin{array}{c}\text { Fineness Modulus } \\
\text { (FM) }\end{array}$ & Density & $\begin{array}{c}\text { Water Absorption } \\
\text { Ratio (\%) }\end{array}$ \\
\hline $\begin{array}{c}\text { Natural fine } \\
\text { aggregate (NFA) }\end{array}$ & 2.45 & 2.60 & 1.0 \\
\hline $\begin{array}{c}\text { Blast furnace slag fine } \\
\text { aggregate (BSFA) }\end{array}$ & 2.30 & 2.80 & 2.1 \\
\hline
\end{tabular}

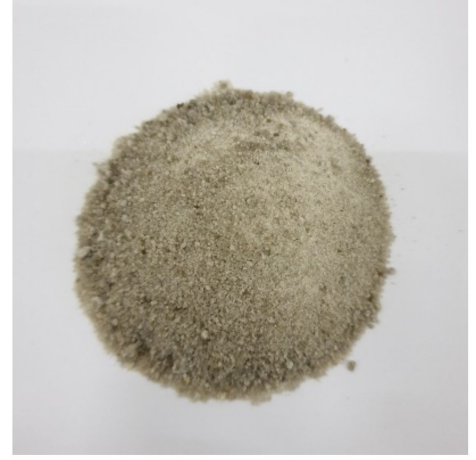

(a)

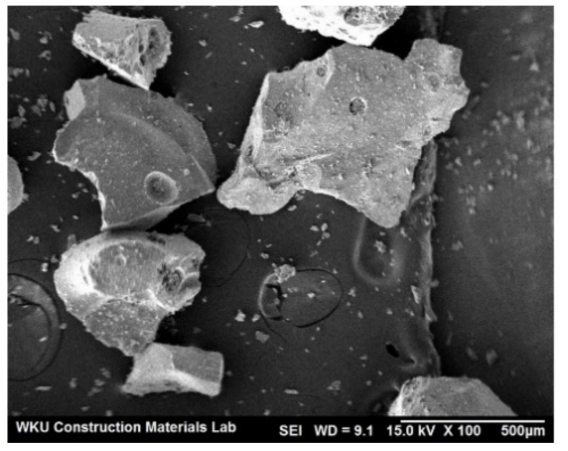

(b)

Figure 1. Blast furnace slag fine aggregate: (a) shape, (b) SEM image

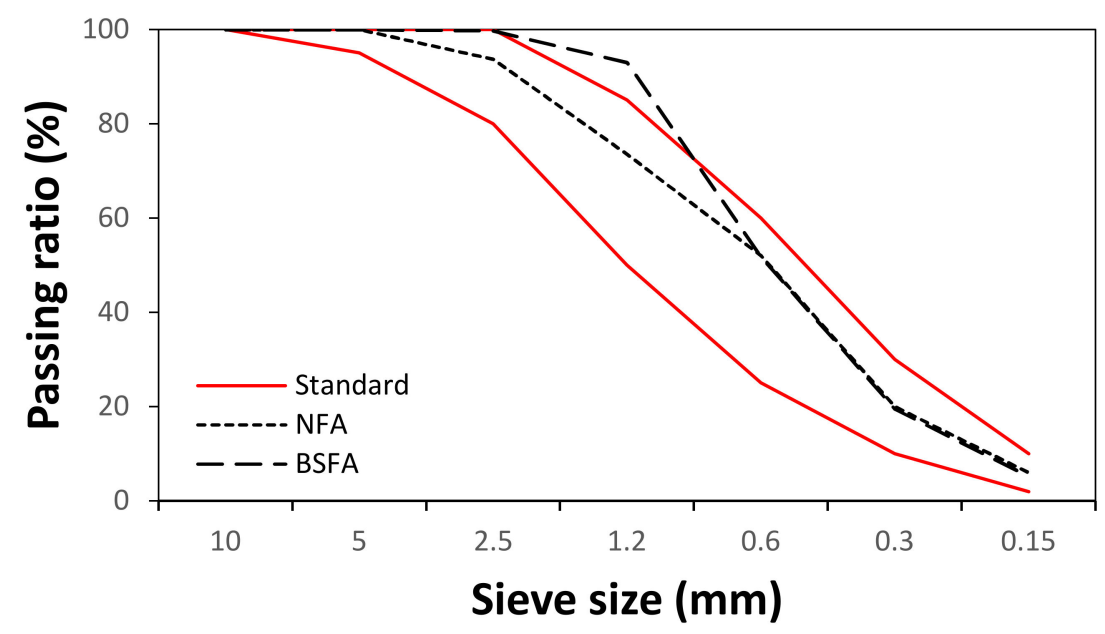

Figure 2. Particle size distribution of fine aggregate.

\subsection{Mixing Proportions and Specimen Preparation}

Table 4 shows the mixture proportion of cement mortar. The water-cement ratio was fixed at $50 \%$, and the sludge content of RW was 5\%, which showed good characteristics in a previous study [17]. RW was used as the mixing water. A mixture of cement mortar without RW and BSFA was used as the control mixture. In the case of cement mortar samples using RW, $0,10,20,30$, and $40 \%$ of BSFA were replaced by the volume of the fine aggregate. In this study, we did not use any chemical admixture. Further, $50 \mathrm{~mm}$ cube specimens were prepared for a compressive strength test, $50 \times 100 \mathrm{~mm}^{2}$ cylindrical specimens were prepared for a split-tensile strength test, $40 \times 40 \times 160 \mathrm{~mm}^{3}$ specimens were prepared for drying shrinkage and carbonation tests, and $100 \times 50 \mathrm{~mm}^{2}$ specimens were prepared for a chloride-ion penetration test. Subsequently, we demolded the specimens after $24 \mathrm{~h}$ and cured them in a water tank at $20^{\circ} \mathrm{C}$ until the required age. 
Table 4. Mix proportion.

\begin{tabular}{cccccccc}
\hline & $\begin{array}{c}\text { BSFA } \\
\mathbf{( \% )}\end{array}$ & $\begin{array}{c}\text { Sludge } \\
\text { Content } \\
(\mathbf{\%})\end{array}$ & $\begin{array}{c}\text { W/C } \\
\mathbf{( \% )}\end{array}$ & $\begin{array}{c}\text { Water } \\
\left(\mathbf{k g} / \mathbf{m}^{3}\right)\end{array}$ & $\begin{array}{c}\text { Cement } \\
\left(\mathbf{k g} / \mathbf{m}^{3}\right)\end{array}$ & $\begin{array}{c}\mathbf{N F A} \\
\mathbf{( k g / \mathbf { m } ^ { 3 } )}\end{array}$ & $\begin{array}{c}\text { BSFA } \\
\mathbf{( k g / \mathbf { m } ^ { 3 } )}\end{array}$ \\
\hline Control & 0 & 0 & & & & 739 & 0 \\
RW5BS0 & 0 & 5 & & 50 & & 739 & 0 \\
RW5BS10 & 10 & 5 & & 170 & & 665 & 80 \\
RW5BS20 & 20 & 5 & & 340 & & 591 & 160 \\
RW5BS30 & 30 & 5 & & & & 448 & 240 \\
RW5BS40 & 40 & 5 & & & & 320 \\
\hline
\end{tabular}

Mortar flow and compressive strength were measured according to KS L 5105 [18], and tensile strength was measured according to KS F 2423 [19]. The presented strength test values are the average values of three samples.

Drying shrinkage was measured using a contact gauge, as shown in Figure 3, according to KS F 2424 [20]. For the carbonation test, the carbonation depth was measured using a phenolphthalein solution after the carbonation process in an accelerated carbonation chamber according to KS F 2584 [21]. In addition, the chloride-ion penetration test was performed according to ASTM C 1202 [22].

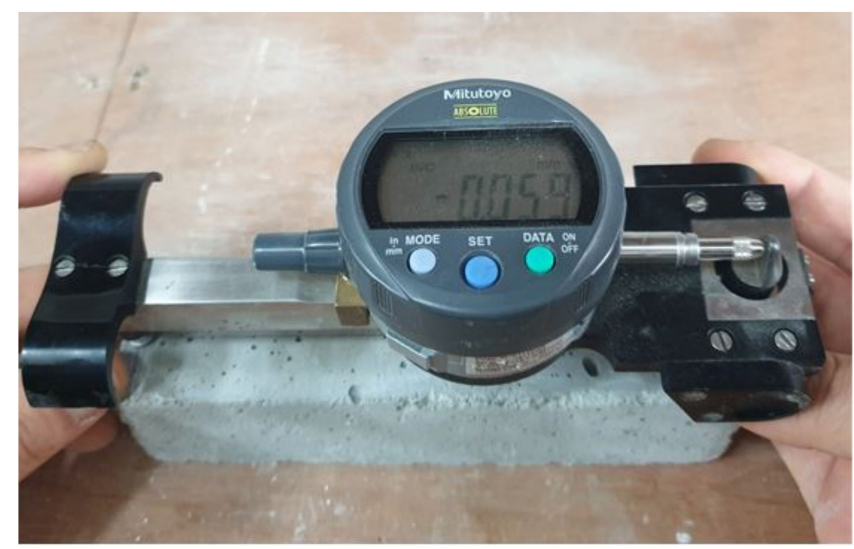

Figure 3. Measurement of drying shrinkage.

\section{Results and Discussion}

\subsection{Mortar Flow}

Figure 4 shows the change in the mortar flow concerning the replacement ratio of BSFA. As shown from the figure, the flow values of the control mixture and RW5BS0 mixture without BSFA were both equal to approximately $184 \mathrm{~mm}$. The flow of the RW5BS40 sample using $40 \%$ of BSFA was approximately $203 \mathrm{~mm}$, which was approximately $12 \%$ higher than that of the control sample. In this study, using RW did not significantly affect the mortar flow, and the mortar flow increased with the replacement ratio of BSFA, which seems to be due to the vitreous properties of blast furnace slag aggregates. 


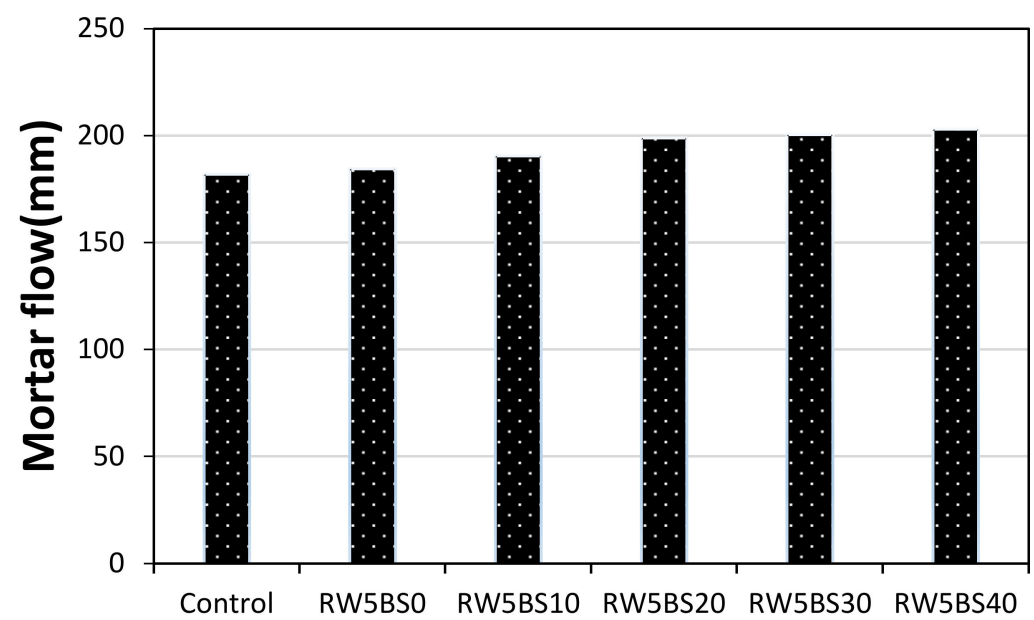

Mix.

Figure 4. Mortar flow.

\subsection{Compressive Strength}

Figure 5 shows the compressive strength of the mortar samples with RW concerning the replacement ratio of BSFA. As shown in the figure, the 7-day compressive strength of the control sample was approximately $38.5 \mathrm{MPa}$, and the compressive strengths of the RW5BS0 and RW5BS10 samples using RW and 0 and $10 \%$ of BSFA were approximately $4-7 \%$ lower than that of the control sample. In contrast, the 7-day compressive strength of the sample using RW and $20 \%$ or more of BSFA was approximately from 38.3 to $39.5 \mathrm{MPa}$, respectively, similar to or somewhat higher than that of the control sample. In the case of an age of 28 days, the compressive strengths of the control sample and the RW5BS0 sample were similar, and the compressive strengths of all the samples using RW and BSFA were higher than that of the control sample.

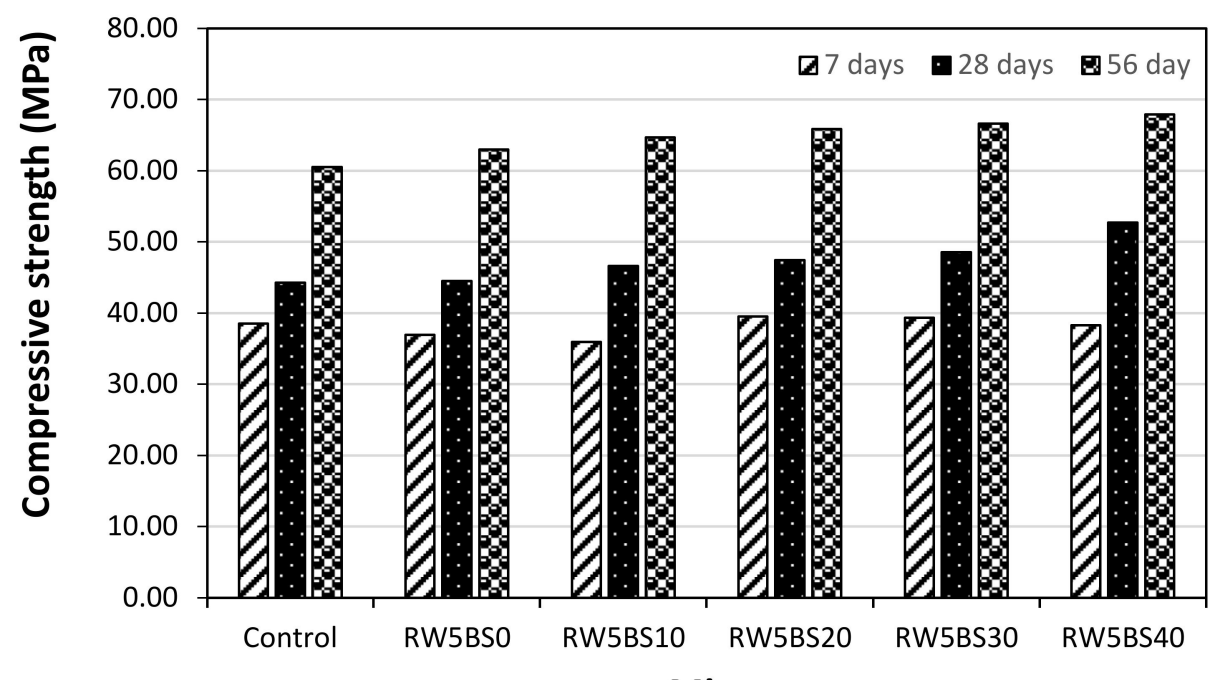

Mix.

Figure 5. Compressive strength.

In particular, the compressive strength of the RW5BS40 sample using RW and $40 \%$ of BSFA was approximately $52.7 \mathrm{MPa}$, which was approximately $18 \%$ higher than that of the RW5BS0 sample using RW and not using BSFA. This tendency was similar at the age of 56 days; that is, the compressive strength of the control sample was the lowest at $60.5 \mathrm{MPa}$, and the compressive strength of the RW5BS0 sample using RW was approximately $4 \%$ 
higher than that of the control sample. In addition, as the replacement ratio of BSFA was increased, the compressive strength of the samples was higher.

The 56-day compressive strength of the sample using 10-40\% BSFA and RW were approximate 3-8\% higher than that of the RW5BS0 sample.

Therefore, when RW and BSFA were used simultaneously, the compressive strength of the cement mortar improved, which is likely because the high alkalinity of the RW improved the reactivity of the BSFA [23-25].

\subsection{Split-Tensile Strength}

Figure 6 shows the 28-day split-tensile strength of the mortar sample using RW concerning the BSFA replacement ratio. As shown in the figure, the tensile strength of the control sample was the lowest at approximately 3.73 MPa. In the case of the split-tensile strength, similar to the tendency of the compressive strength, the split-tensile strength of the samples increased with the BSFA replacement ratio. The split-tensile strengths of the RW5BS30 and RW5BS40 samples using more than 30\% of BSFA were $3.93 \mathrm{MPa}$ and 4.24 MPa, respectively, which were about $5-14 \%$ higher than that of the control sample.

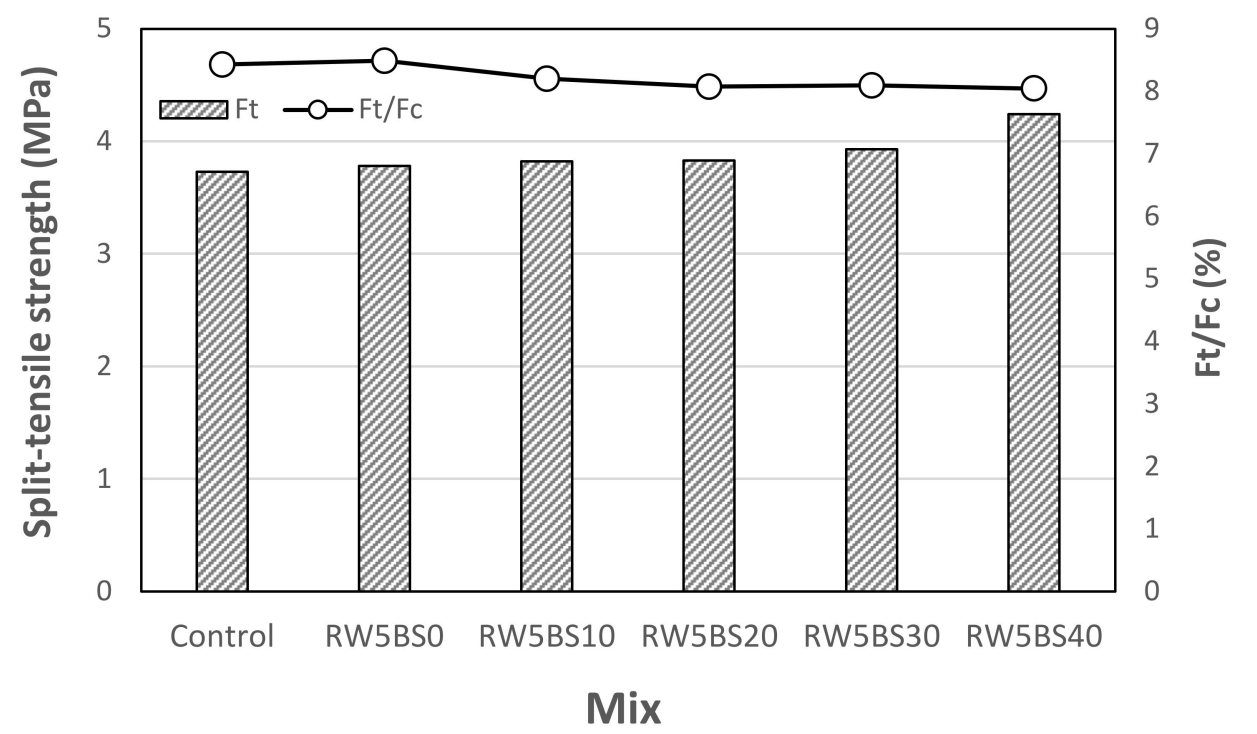

Figure 6. Split-tensile strength.

In general, the tensile strength of the samples using BSFA was relatively higher than that of the control sample, but the ratio of tensile strength to compressive strength was approximately $8.0-8.4 \%$ regardless of the BSFA use.

\subsection{Drying Shrinkage}

Figure 7 shows the change in the drying shrinkage of the mortar samples with RW and BSFA.

After an age of 56 days, the drying shrinkage of the control sample was approximately $0.142 \%$, and the drying shrinkage of the RW5BS0 sample using RW without BSFA was $0.133 \%$, which was lower than that of the control sample. In the case of the mixtures using RW and BSFA simultaneously, the drying shrinkages of the RW5BS10 and RW5BS20 samples using 10 and $20 \%$ of BSFA were approximately $0.128-0.130 \%$, which was relatively lower than that of the control sample. The drying shrinkages of the RW5BS30 and RW5BS40 samples using 30 and $40 \%$ of BSFA were approximately $0.142-0.144 \%$, similar to the control sample. Therefore, in this study, it was found that when the replacement ratio of BSFA was lower than $20 \%$, the drying shrinkage of cement mortar using RW was effectively reduced. 


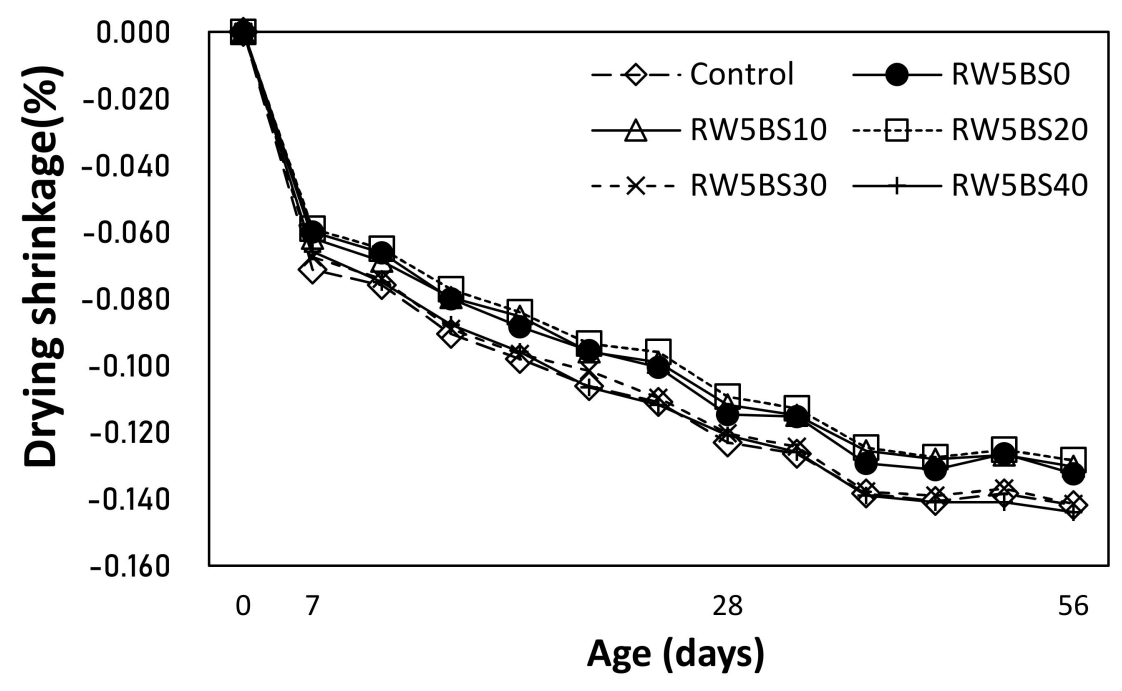

Figure 7. Drying shrinkage.

\subsection{Accelerated Carbonation Depth}

Figure 8 shows the carbonation depth of the samples using RW concerning the BSFA replacement ratio after 28 days of the accelerated carbonation test. As shown in the figure, the carbonation depth of the control sample was approximately $0.97 \mathrm{~mm}$, which was the largest, and the carbonation depth of the RW5BS0 sample using RW without BSFA was approximately $0.86 \mathrm{~mm}$, which was approximately $11 \%$ lower than that of the control sample. In the case of the samples using RW, as the BSFA replacement ratio was increased, the carbonation depth of the samples decreased, and the accelerated carbonation depth of the RW5BS40 sample using RW and $40 \%$ of BSFA was the lowest at approximately $0.56 \mathrm{~mm}$. In general, as the compressive strength of the sample was increased, the carbonation depth tended to decrease.

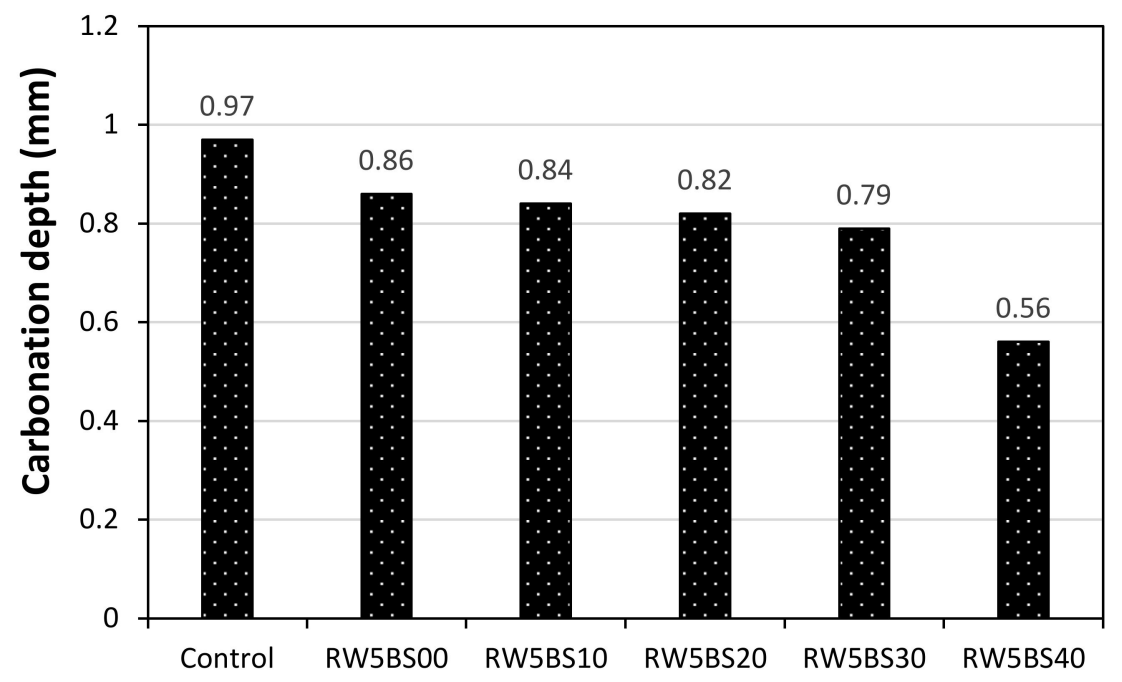

\section{Mix.}

Figure 8. Accelerated carbonation depth.

\subsection{Chloride-Ion Penetrability}

Figure 9 shows the variation in the chloride-ion penetrability of the sample concerning the BSFA replacement ratio after an age of 28 days. The total charge passed through the sample was calculated according to ASTM C 1202. The charge passed through the control sample was approximately 9865 C, and the charge passed through the RW5BS0 sample using RW without BSFA was approximately 11,381 C, which was approximately $15 \%$ 
higher than that of the control sample. However, in the mixtures using RW and BSFA, the charge passed through the sample tended to decrease gradually as the BSFA replacement ratio was increased. The charge passed through the samples using more than $20 \%$ of BSFA was approximately from 6667 to $9731 \mathrm{C}$, which was lower than the charge passed through the control sample. In particular, in the RW5BS30 sample using 30\% of BSFA and RW, the charge passed through the sample was approximately $6667 \mathrm{C}$, which was approximately $32 \%$ lower than that of the control sample. Therefore, when only RW is used in cement mortar, it may be detrimental to its chloride ion penetration resistance, but the simultaneous use of BSFA and RW in cement mortar is expected to increase the chloride ion penetration resistance of the sample.

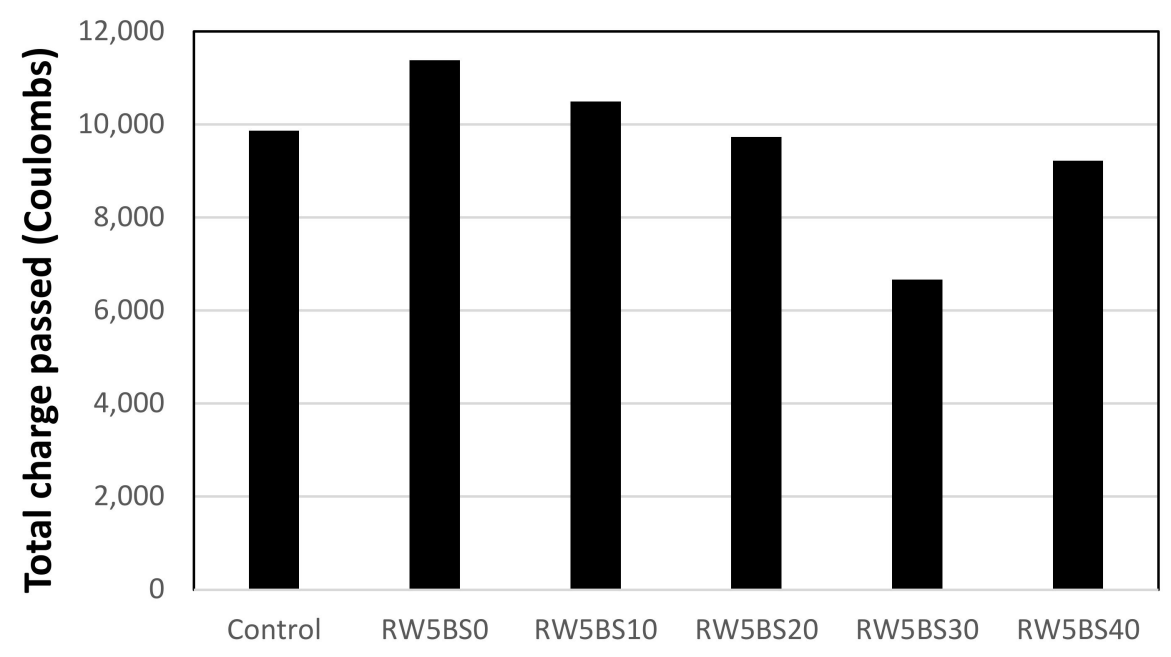

Mix.

Figure 9. Chloride ion penetrability.

\section{Conclusions}

The conclusions of this study can be summarized as follows:

(1) In this study, using RW did not significantly affect the mortar flow, but the mortar flow increased with the replacement ratio of BSFA, which seems to be due to the vitreous properties of blast furnace slag aggregates;

(2) The 28-day compressive strengths of the control sample and RW5BS0 sample were similar, and the compressive strengths of all the samples using RW and BSFA were higher than that of the control sample. Further, the split-tensile strengths of the samples increased with the BSFA replacement ratio, similar to the tendency of the compressive strength;

(3) It was found that when the replacement ratio of BSFA was lower than $20 \%$, the drying shrinkage of the cement mortar using RW was effectively reduced. In the case of the samples using RW, as the BSFA replacement ratio was increased, the carbonation depth of the samples decreased, and the accelerated carbonation depth of the RW5BS40 sample using RW and 40\% of BSFA was the lowest at approximately $0.56 \mathrm{~mm}$;

(4) In the case of the mixtures using RW and BSFA, the charge passed through the sample tended to decrease gradually as the BSFA replacement ratio was increased;

(5) Therefore, when RW and BSFA are used properly, it is expected that the mechanical properties of cement mortar, carbonation resistance, and chloride ion penetration resistance can be enhanced.

However, further studies are required to establish the strength development mechanism and the relationship between chloride penetration resistance, durability and chemical composition of materials, water-binder ratio, and alkali content, among other factors. 
Author Contributions: Conceptualization, S.-J.C.; Investigation, S.-J.C., J.-I.L., and S.-H.B.; Data Curation, J.-H.K.; Writing-Original Draft Preparation, S.-J.C. and J.-H.K.; Writing-Review \& Editing, S.-J.C. All authors have read and agreed to the published version of the manuscript.

Funding: This paper was supported by Wonkwang University in 2020.

Institutional Review Board Statement: Not applicable.

Informed Consent Statement: Not applicable.

Data Availability Statement: Not applicable.

Acknowledgments: The authors gratefully acknowledge Wonkwang University for the financial support of this work.

Conflicts of Interest: The authors declare no conflict of interest.

\section{References}

1. Min, T.B. An Experimental Study on the Development of EMP Shielding Concrete According to the Types of Aggregates of Industrial By-products. J. Korean Recycl. Constr. Resour. Inst. 2020, 8, 310-316.

2. Lee, B.K.; Kim, G.Y.; Koo, K.M.; Shin, K.S. Properties of Compressive Strength of Mortar Based on High-activated Blast Furnace Slag using the Slag by-product as an Activator. J. Korea Inst. Build. Constr. 2014, 14, 37-44. [CrossRef]

3. Cho, W.J.; Ann, K.Y. A Study on the Hydration Characteristics and Fundamental Properties of Ternary Blended Cement Using Ferronickel Slag and Fly Ash. J. Korea Concr. Inst. 2020, 32, 27-35. [CrossRef]

4. Siddipue, R. Utilization of Industrial By-products in Concrete. Procedia Eng. 2014, 95, 335-347. [CrossRef]

5. Kim, G.H.; Kim, K.J.; Lee, M.H.; Lee, S.H.; Han, C.G. Properties of cement mortar with solid content and leaving time of recycling water using stabilizing agent. JAIK 2013, 23, 355-358.

6. Sandrolini, F.; Franzoni, E. Waste wash water recycling in ready-mixed concrete plants. Cem. Concr. Res. 2001, 31, 485-489. [CrossRef]

7. Yang, E.I.; Park, J.H.; Kim, K.L.; Cho, G.J. Durability and Strength Characteristics of Concrete Using Sludge Water above Specification. J. Korea Concr. Inst. 2006, 18, 199-204. [CrossRef]

8. Ekolu, S.O.; Dawneerangen, A. Evaluation of recycled water recovered from a ready-mix concrete plant for reuse in concrete. J. S. Afr. Inst. Civ. Eng. 2010, 52, 77-82.

9. Oh, T.G.; Kim, J.H.; Bae, S.H.; Choi, S.J. A Study on the Strength, Drying Shrinkage and Carbonation Properties of Lightweight Aggregate Mortar with Recycling Water. J. Korea Inst. Build. Constr. 2020, 20, 391-397.

10. Lee, S.H.; Jung, Y.W.; Yeo, I.D.; Choi, J.O.; Bae, S.H. Physical Properties of Shale Aggregate and Characteristics of Concrete in Replacement Ratio in Daegu-Kyeongbuk Region. J. Korea Acad. Ind. Coop. Soc. 2020, 13, 5551-5557.

11. Park, K.T.; Han, M.C.; Hyun, S.Y. Analysis the Use of Concrete Fine Aggregates of Coal Gasification Slag. J. Korean Recycl. Constr. Resour. Inst. 2019, 7, 101-108.

12. Yüksel, İ.; Bilir, T.; Özkan, Ö. Durability of concrete incorporating non-ground blast furnace slag and bottom ash as fine aggregate. Build. Environ. 2007, 42, 2651-2659. [CrossRef]

13. Valcuende, M.; Benito, F.; Parra, C.; Miñano, I. Shrinkage of self-compacting concrete made with blast furnace slag as fine aggregate. Constr. Build. Mater. 2015, 76, 1-9. [CrossRef]

14. Hiraskar, K.G.; Patil, C. Use of Blast Furnace Slag Aggregate in Concrete. Int. J. Appl. Eng. Res. 2013, 4, 95-98.

15. Nataraja, M.C.; Dileep Kumar, P.G.; Manu, A.S.; Sanjay, M.C. Use of granulated blast furnace slag as fine aggregate in cement mortar. Int. J. Struct. Civ. Eng. Res. 2013, 2, 59-68.

16. Ryou, J.S.; Song, H.H.; Kim, S.S.; Lee, J.B. New technology of blastfurnace slag activation with recycling water from ready-mixed concrete production. Cem. Wapno Beton 2013, 18, 33-38.

17. Oh, T.G.; Bae, S.H.; Lee, D.G.; Choi, S.J. The Fluidity and Compressive Strength Properties of Lightweight Mortar Using Recycling Water for Pre-wetting of Artificial Lightweight Aggregate. J. Korea Inst. Build. Constr. 2019, 19, 153-154.

18. KS L 5105. Testing Method for Compressive Strength of Hydraulic Cement Mortars; Korea Industrial Standards; Korean Standards \& Certification Information Center: Seoul, Korea, 2007; 5 p.

19. KS F 2423. Standards Test Method for Tensile Splitting Strength of Concrete; Korea Industrial Standards; Korean Standards \& F 2423; Standards \& Certification Information Center: Seoul, Korea, 2016; 12p.

20. KS F 2424. Standard Test Method for Length Change of Mortar and Concrete; Korea Industrial Standards; Korean Standards \& Certification Information Center: Seoul, Korea, 2015.

21. KS F 2584. Standard Test Method for Accelerated Carbonation of Concrete; Korea Industrial Standards; Korean Standards \& Certification Information Center: Seoul, Korea, 2015.

22. ASTM C 1202. Standard Test Method for Electrical Indication of Concrete's Ability to Resist Chloride Ion Penetration; American Society for Testing and Materials: West Conshohocken, PA, USA, 2019.

23. Fang, S.; Lam, E.S.S.; Li, B.; Wu, B. Effect of alkali contents, moduli and curing time on engineering properties of alkali activated slag. Constr. Build. Mater. 2020, 249, 1-9. [CrossRef] 
24. Mohamed, O.A. A review of durability and strength characteristics of alkali-activated slag concrete. Materials 2019, $2019,1198$. [CrossRef] [PubMed]

25. Puertas, F.; Palacios, M.; Gil-Maroto, A.; Vazquez, T. Alkali-aggregate behavior of alkali-activated slag mortars: Effect of aggregate type. Cem. Concr. Compos. 2009, 31, 277-284. [CrossRef] 